\title{
A comparative study among methods used for wheat flour analysis and for measurements of gluten properties using the Wheat Gluten Quality Analyser (WGQA)
}

\author{
Maria Cristina FERRARI ${ }^{1}$, Maria Teresa Pedrosa Silva CLERICI $^{1 \star}$, Yoon Kil CHANG ${ }^{1}$
}

\begin{abstract}
This study aimed at comparing both the results of wheat flour quality assessed by the new equipment Wheat Gluten Quality Analyser (WGQA) and those obtained by the extensigraph and farinograph. Fifty-nine wheat samples were evaluated for protein and gluten contents; the rheological properties of gluten and wheat flour were assessed using the WGQA and the extensigraph/farinograph methods, respectively, in addition to the baking test. Principal component analysis (PCA) and linear regression were used to evaluate the results. The parameters of energy and maximum resistance to extension determined by the extensigraph and WGQA showed an acceptable level for the linear correlation within the range from 0.6071 to 0.6511 . The PCA results obtained using WGQA and the other rheological apparatus showed values similar to those expected for wheat flours in the baking test. Although all equipment used was effective in assessing the behavior of strong and weak flours, the results of medium strength wheat flour varied. WGQA has shown to use less amount of sample and to be faster and easier to use in relation to the other instruments used.
\end{abstract}

Keywords: wheat flour; rheological property; gluten; quality evaluation; baking test.

\section{Introduction}

Wheat, a noble cereal of high global consumption, is produced in quantity and quality by a few countries and imported by developing countries, which in most cases do not have enough production to supply the internal market (Associação Brasileira da Indústria do Trigo, 2014; Food and Agriculture Organization of the United Nations, 2013). Wheat plays an important role as global commodity (Food and Agriculture Organization of the United Nations, 2013) due to its glutenforming proteins, which are capable of having extensibility and elasticity required for bakery products and pasta (Costa et al., 2008). In 2012, from the total of 2305.1 million tonnes of cereals produced in the world, wheat accounted for 675.1 million tonnes (Food and Agriculture Organization of the United Nations, 2013), and its main product, wheat flour, is widely used for human consumption. A total of $55 \%$ of processed wheat flour is estimated to be used in the baking and confectionery industry, $17 \%$ is used for domestic consumption, $15 \%$ for dough, $11 \%$ for cookies and $2 \%$ for the production of drugs, glue, and animal feeding (Associação Brasileira da Indústria do Trigo, 2014).

Wheat flour quality is directly related to the wheat gluten formed by mixing the flour with water and with the use of appropriate application of mechanical work to form a viscoelastic network, whose structure is the basis for bakery products and pasta (Bloksma, 1990; Dobraszczyk et al., 2001).

Although rye, barley, oat, and triticale have gluten-forming proteins in their composition, only wheat has sufficient amounts (7-17\%) for the formation of a strong gluten network, which differentiates it from other cereals (Dendy \& Dobraszczyk, 2001). The quantity and quality of gluten is among the main parameters to be investigated in order to determine the quality of the final product. In addition, large investments have been made to develop analysis and equipment to determine the strength of wheat flour proteins through extensibility and resistance to extension of gluten and dough. Viscosity and elasticity are the most important characteristics with respect to the quality of the final product (Fufa et al., 2005; Módenes et al., 2009; Camargo \& Camargo, 1987).

Kress (1924) was one of the pioneers to develop an apparatus to test gluten, and the experimental test to assess gluten quality was conducted by James \& Huber (1927). Later, the Brabender Glutograph was developed by Mohs et al. (1939). A device to measure the flow and elasticity of raw gluten was described by Baker et al. (1942) and later by Baker et al. (1943). In 1946, an apparatus called "Stretchometer" was devised by Hlynkla \& Anderson (1946) to measure the extensibility of raw gluten and its resistance to extension. Udy (1953) used a Jolly balance to study purified gluten cylinders. Sietz \& Dorfner (1987) used the extension-charge test on gluten samples.

Currently, many tests have been carried out, and the results are correlated with performance in bakery to obtain high quality products (Módenes et al., 2009; Camargo \& Camargo, 1987). Although the extensigraph and farinograph methods are used to assess the quality of wheat flour (Chang \& Ferrari, 2000) with good representation of results, they use large amounts of sample and take long time to produce results. In addition, they are not always accessible to units receiving the grain; the automated systems that evaluate the gluten index, such as the glutomatic sytem, which are an indicator of the gluten strength, use smaller amount of samples, and are faster to predict the quality of the flour.

\footnotetext{
Received 12 Nov., 2013

Accepted 06 Feb., 2014 (006155)

Cereal Laboratory, Department of Food Technology, School of Food Engineering, State University of Campinas - UNICAMP, CEP 13083-862, Campinas, SP, Brazil, e-mail: mariateresapedrosa@gmail.com

${ }^{*}$ Corresponding author
} 
Therefore, in Brazil, Chang (1994) developed the Wheat Gluten Quality Analyser (WGQA) to quickly evaluate the gluten strength using the wet gluten, which can be obtained manually or using a glutomatic system, provided that the official methods of analysis are used.

This paper aimed to study the feasibility of using the WGQA to evaluate the rheological properties of gluten from wheat samples in comparison with the extensigraph and farinograph official methods, as well as using the baking test.

\section{Materials and methods}

\subsection{Materials}

Wheat

Fifty-nine samples of wheat from Argentina, USA, Canada, and Brazil were obtained from a commercial milling company (Braswey Milling Company - Campinas- S.P., Brazil). The samples were identified from 1 to 9 , from $A$ to $Z$, and from a to $\mathrm{z}$.

Wheat was stored at $14 \%$ relative humidity $(\mathrm{RH})$ for 12 hours and milled in a laboratory-scale Quadrumat Senior-Mill (C.W. Brabender), and the reduction flour was used for analysis and baking.

Other ingredients including commercial instant dry yeast, hydrogenated vegetable fat, refined sugar, and salt were used in the baking test.

\subsection{Methods}

Physicochemical analyses

Protein content

The semi-micro-Kjeldahl method was used for determination of nitrogen in wheat flour accordding to the AACC method 46-13 (American Association for Clinical Chemistry, 1995), and protein content was calculated by multiplying the nitrogen content by a conversion factor (5.7).

\section{Gluten content}

The AACC method 38-12 (American Association for Clinical Chemistry, 1995) was used to determine the gluten content of $25 \mathrm{~g}$ of wheat flour samples.

\section{Rheological tests}

Wheat flour assessment

The rheological characteristics of the mixture of wheat flour and water resulting in a dough were analyzed as follows:

- farinographic analysis by the AACC method 54-21 (American Association for Clinical Chemistry, 1995); the farinogram parameters were: hydration capacity of flour (ABS), development time (TD), stability (EST), and tolerance index (IT). All parameters were measured using $300 \mathrm{~g}$ of wheat flour ( $14 \%$ moisture).The test was performed two times: one for measurement of ABS and the other for the complete test.

- extensigraphic analysis by the AACC method 54-10 (American Association for Clinical Chemistry, 1995), and the parameters measured were: resistance to extension (RE), maximum resistance to extension (RME), extensibility (EXE), and energy (A). All parameters were measured after 45,90 , and $135 \mathrm{~min}$ of rest period.

\section{Gluten strength by WGQA}

The Wheat Gluten Quality Analyser (WGQA) was specially designed to evaluate gluten viscoelasticity. This equipament has a dynamometer, which stretches the gluten sample until its rupture, measuring the strength produced during stretching. The strength transducer was calibrated using several known weights attached to a hook. The method used to determine the gluten protein strength in the Wheat Gluten Quality Analyser (WGQA) was reported by Chang (1994) and Chang \& Ferrari (2000). The prototype was designed to measure the maximum resistance to extension (RMP) in N, extensibility (EXP) in mm, and energy (ENP) in J.

\section{Baking test}

The breads were produced according to the method described by El-Dash (1978), with some modifications; the follwing parameters were measured: loaf specific volume $\left(\mathrm{cm}^{3} / \mathrm{g}\right.$ ), crust external characteristics (maximum value of 35 points), and crumb internal characteristics (maximum value of 40 points), assuming that these assessments would reach the total score of 75 points. Flavour and smell characteristics were not considered.

\section{Statistical analysis}

Physicochemical analyses were performed in triplicate, and the results were expressed as mean values and standard deviation.

The principal component analysis (PCA) and the Pearson's linear correlation $(\mathrm{p}<0.05)$ were used to test the rheological properties measured by the WGQA, extensigraph, farinograph, and baking test using SAS $^{\circledast}$ (Statistical Analisys System Institute, 1990).

\section{Results and discussion}

\subsection{Protein content}

The protein content of wheat flour is of great importance because it requires small amounts of sample. It is simply determined and is related to the gluten strength thus allowing predicting its industrial quality (Fufa et al., 2005). In general, total protein content contains around $80 \%$ gluten-forming proteins (Pomeranz, 1988). 
Both protein and wet gluten contents of the samples are presented in Table 1. The protein contents varied from $6.56 \%$ (sample y) to $15.40 \%$ (sample $\mathrm{h}$ ), with an average value of $11.14 \%$.

This broad range in protein content suggests there are flours for different applications, including cakes and biscuits (lower values), breads (10-12\%), and pastas and whole wheat bread (>14\%) (Pomeranz, 1988) although the protein content suitable for bakery products should be between 10.5 and $13 \%$ (Schiller, 1984).

As can be seen in Table 1, from the 59 flour samples, only flour $h$ is appropiate for pasta and whole wheat bread, while 47 flour samples can be used for bread manufacturing and the remaining samples can be used for cakes and bicuits.

Cereal chemists are aware that not only quantity but also quality of gluten protein is a specially important factor in producing good quality products (Pratt, 1971; Schmidt et al., 2009). Thus, other assessments, such as determination of gluten content, are required for wheat flour.

\subsection{Wet gluten content}

Among the wheat quality components, gluten plays the most important role in determining industrial use, and therefore gluten strength is one of the parameters for classification of wheat for use in bread, cakes, and pasta (Pomeranz, 1988; Pratt, 1971; Módenes et al., 2009).

The content of wet gluten of the samples is presented in Table 1 . The results ranged from $21.56 \%$ (sample $m$ ) to $49.36 \%$ (sample $n$ ), with an average value of $37.61 \%$. According to
Pomeranz (1988) and Pratt (1971), wheat gluten has relatively constant water absorption capacity (approximately 2.8 times the dry gluten content); therefore, the content of dry gluten in the samples ranged from 7.7 to $17.63 \%$.

As shown in Table 1, the total protein content should not be used to assess the gluten content since although samples $b$, $d$, and $h$ had higher gluten content, only sample $h$ had higher protein content.

In order to evaluate the quality of gluten, it is necessary to determine the rheological properties of elasticity and extensibility.

\subsection{Rheological properties of wheat flour dough}

Brabender farinograph and extensigraph were used worldwide to monitor the wheat flour quality. The parameters analyzed, such as development time (TD), stability (EST), and resistance to extension (RE) which have been described in the AACC (American Association for Clinical Chemistry, 1995) and are used to define wheat types and wheat flour quality, as reported by Oliver \& Allen (1992) and Williams et al. (1988).

Farinographic analysis showed that the flours ranged from weak to strong, once TD ranged from 60 s (sample $D$ ) to 660 s (sample $K$ ) and EST ranged from 20s (samples $E$ and $F$ ) to 1320 s (sample $S$ ). The higher the time values obtained from these two parameters, the greater the strength of the flour.

The extensigraphic parameters of the dough increased during the rest period, as expected, from 45 to $135 \mathrm{~min}$; RE varied from 115 to 5850 U.E, RME from 140 to 880 U.E, EXE from 133 to $241 \mathrm{~mm}$, and Energy (A) from 0.31 to $1.84 \mathrm{dm}^{2}$.

Table 1. Protein content ${ }^{\mathrm{a}}$ and Wet gluten content of the wheat flour ${ }^{\mathrm{b}}$ samples.

\begin{tabular}{|c|c|c|c|c|c|c|c|c|}
\hline Samples & Protein $(\%)^{b}$ & Wet gluten(\%) & Samples & Protein (\%) & Wet gluten (\%) & Samples & Protein (\%) & Wet gluten (\%) \\
\hline 1 & 11.59 & 43.96 & $\mathrm{~L}$ & 11.66 & 44.56 & $\mathrm{f}$ & 10.70 & 40.04 \\
\hline 2 & 10.44 & 35.16 & M & 10.49 & 35.86 & $\mathrm{~g}$ & 10.43 & 38.82 \\
\hline 3 & 10.88 & 34.50 & $\mathrm{~N}$ & 11.34 & 41.50 & $\mathrm{~h}$ & 15.40 & 43.60 \\
\hline 4 & 11.12 & 35.20 & $\mathrm{O}$ & 10.81 & 33.98 & $\mathrm{i}$ & 11.47 & 41.30 \\
\hline 5 & 11.00 & 38.34 & $\mathrm{P}$ & 10.42 & 34.82 & $\mathrm{j}$ & 10.69 & 42.68 \\
\hline 6 & 11.08 & 43.36 & Q & 12.62 & 34.80 & $\mathrm{k}$ & 10.60 & 33.30 \\
\hline 7 & 11.61 & 36.90 & $\mathrm{R}$ & 9.94 & 42.44 & 1 & 13.43 & 30.48 \\
\hline 8 & 7.24 & 36.38 & $\mathrm{~S}$ & 13.52 & 34.34 & $\mathrm{~m}$ & 12.68 & 21.56 \\
\hline 9 & 7.22 & 41.42 & $\mathrm{~T}$ & 10.94 & 29.04 & $\mathrm{n}$ & 13.12 & 49.36 \\
\hline A & 9.25 & 30.28 & $\mathrm{U}$ & 11.32 & 45.28 & o & 12.88 & 44.58 \\
\hline B & 12.61 & 41.96 & $\mathrm{~V}$ & 9.67 & 40.76 & $\mathrm{p}$ & 12.91 & 43.00 \\
\hline C & 8.80 & 23.94 & $\mathrm{~W}$ & 12.91 & 40.36 & $q$ & 11.28 & 30.38 \\
\hline $\mathrm{D}$ & 8.83 & 23.50 & $\mathrm{X}$ & 10.91 & 34.80 & $\mathrm{r}$ & 9.83 & 32.94 \\
\hline $\mathrm{E}$ & 11.85 & 42.32 & $\mathrm{Y}$ & 6.56 & 32.00 & $\mathrm{~s}$ & 12.56 & 40.02 \\
\hline $\mathrm{F}$ & 11.07 & 42.36 & Z & 10.62 & 41.40 & $\mathrm{t}$ & 9.56 & 41.62 \\
\hline $\mathrm{G}$ & 12.39 & 39.70 & $\mathrm{a}$ & 12.69 & 40.24 & $\mathrm{u}$ & 12.70 & 30.40 \\
\hline $\mathrm{H}$ & 11.11 & 40.80 & $\mathrm{~b}$ & 9.50 & 43.98 & $\mathrm{~V}$ & 13.25 & 35.78 \\
\hline I & 8.65 & 28.00 & $c$ & 10.71 & 40.32 & $\mathrm{w}$ & 12,03 & 31.84 \\
\hline $\mathrm{J}$ & 11.58 & 36.40 & $\mathrm{~d}$ & 11.63 & 44.40 & $\mathrm{x}$ & 12.85 & 38.46 \\
\hline $\mathrm{K}$ & 9.39 & 37.18 & $\mathrm{e}$ & 13.14 & 42.50 & & & \\
\hline
\end{tabular}

${ }^{a}$ Nitrogen $x$ 5,7. ${ }^{b}$ Mean of three replicates. 
According to these parameters, flour classification ranged from weak to strong.

The parameters in the WQGA showed that the maximum resistance to extension (RMP) varied from 0.28 to $1.73 \mathrm{~N}$; extensibility (EXP) from 52 to $181 \mathrm{~mm}$, and Energy (ENP) from 0.024 to $0.142 \mathrm{~J}$. These values showed that gluten exhibited similar behavior to those of wheat flours, varying in strength from weak to strong. Principal component analysis (PCA) and linear regression were used to evaluate the relationship between the results obtained by the WGQA, extensigraph, and farinograph.

\subsection{Statistical analysis of the rheological instruments}

The results and the PCA graph of the parameters obtained by the WGQA and farinograph are shown in Figure 1a. When WGQA and farinograph were compared, the first principal component (CP1) accounted for $44.7 \%$ of the total range, while the second principal component (CP2) accounted for $23.1 \%$. Therefore, CP1 and CP2 together accounted for $67.8 \%$ of the total range. Figure 1a shows that the vector tolerance index (IT) and the extensibility (EXP) were located in quadrant II. The other parameters registered, developing time (TD), stability (EST), and RMP, were located in quadrant IV. The second component (CP2) attributed great significance to the parameters absortion (ABS) and energy (ENP). On axis CP1, the most important parameters were EST and IT, whilst on $\mathrm{CP} 2$, they were
EXP and ENP. As can be seen in this figure, the PMR (WQGA), and TD and EST (farinograph) vectors are located together and similarly affected the rheological behavior of the samples. The same occured for the parameters ENP and EXP (WQGA) and ABS (farinograph). In contrast, the parameter IT (farinograph) showed an inverse relationship with the parameter RMP.

Few samples stood out in terms of quality in the PCA analysis (Figure 1a) because the majority showed intermediate characteristics of quality. Samples $F, E, 7, N, 6$, and $D$ were considered weak; samples $O, o, t, b$, and $Q$ affected the direction and length of the vector of the ABS due to higher values, and $S, p$, and $B$ were stronger and therefore affected the vectors of TD, RMP and EST.

PCA, in Figure 1b, shows the comparison between the parameters obtained by the WGQA and extensigraph. CP1 accounted for $64.4 \%$ of the total range, whilst CP2 accounted for $19.3 \%$. Therefore, when considered together, CP1 and CP2 accounted for $83.7 \%$ of the total range. The majority of the vectors of similar parameters registered using different equipment were located in the same quadrant.

These average variables measuring similar attributes were located in close proximity, and therefore showed a similar trend with respect to the rheological measurements, regardless of the equipment used in the analysis. As for extensibility, all vectors were located in quadrant II, regardless of the equipment used: WGQA (EXP) or extensigraph (EXE1, EXE2, and EXE3).
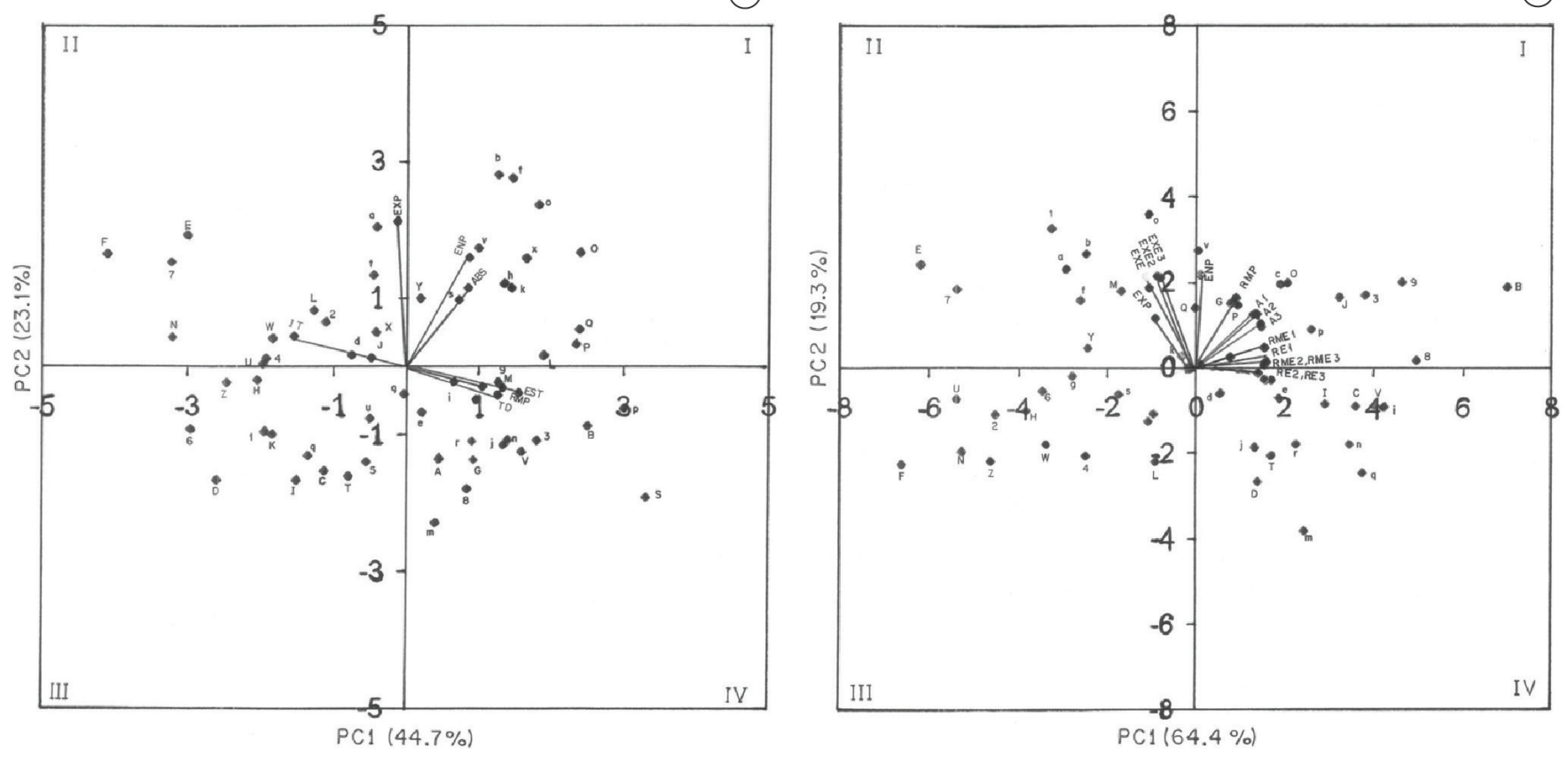

Figure 1. PCA graph of the parameters obtained by the WGQA and farinograph (a), and WGQA and extensigraph (b). Where: RMP, EXP and ENP = maximum resistance to extension, extensibility, and energy respectively, obtained by WGQA; ABS, TD, EST, and IT = absorption, development time, stability, and tolerance index, respectively, obtained by the farinograph; RE1, RE2, RE3 = resistance to extension, at 45 , 90, and 135 minutes, respectively; RME 1, RME2, RME3 = maximum resistance to extension at 45, 90, and 135 minutes, respectively; EXE 1, EXE2, EXE3 = extensibility at 45, 90, and 135 minutes, respectively; Al, A2, A3 = energy at 45, 90, and 135 minutes, respectively, obtained by the extensigraph. 
Moreover, CP1 atributed similar significance for all extensigraph vectors analyzed. The variable energy registered by the extensigraph (E1, E2, E3) and by the WGQA (ENP) was located in quadrant I. The variable energy at 45, 90, and 135 minutes (A1, A2, and A3, respectively) showed similar significance, and its vectors were located between $\mathrm{CP} 1$ and $\mathrm{CP} 2$ axis, $\mathrm{A} 2$ and $\mathrm{A} 3$, practically overlapping. A slight angle was formed between the vector $\mathrm{ENP}$ and the $\mathrm{CP} 2$ axis.

Slight angles were formed between the variables resistence to extension (RE) and maximum resistence to extension (RME) and the CP1 axis, and the vectors RE1, RME1, and RME2 and RME3 were located in quadrant I and the vectors RE2 and RE3 in quadrant IV. The RMP vector was located in quadrant I, between $\mathrm{CP} 1$ and $\mathrm{CP} 2$ axes. In general, the most important variables of the $\mathrm{CP} 1$ and $\mathrm{CP} 2$ axis were represented by $\mathrm{RE}$ and RME, and ENP, EXP and EXE1, EXE2, and EXE3, respectively.

The parameters RMP (WQGA) and A1, A2, and A3 (farinograph) affected the distribution of the samples in a similar way, which was also observed for the parameters ENP (WQGA) and EXE1, EXE2, and EXE3. Based on the distribution of the samples, it appears that most are distributed around the central region, evidencing that they have moderate strength, while the samples with greater emphasis on these properties were samples $B, 8$, and 9 , which were considered strong; samples $1, b$, and $a$,

Table 2. Classification of the samples analyzed by the farinograph.

\begin{tabular}{cc}
\hline Samples & $\begin{array}{c}\text { Classification by } \\
\text { Williams et al. (1988) }\end{array}$ \\
\hline S,V,p & Strong \\
$\begin{array}{c}\text { 3,8,9,B,P,Q, 4,5,A,G,I,J,K,L,M,O,R,T,W,Y,a,b, } \\
\text { C,d,e,f,g,h,I,j,k,l,m,n,o,r,s,t,u,v,w, x, 1,2,6,C, } \\
\text { H,U,X,Z, q, D,F,N }\end{array}$ & Medium \\
7,E & Weak \\
\hline
\end{tabular}

which affected the EXE due to higher values; and samples $E$, $7, F, N$, and $U$, which showed characteristics of weak flours, influencing the responses due to lower values.

Table 2 shows the strength classification of the flour according to the parameters analyzed by the farinograph, which confirms the large number of medium strength flour results. These flours cause major changes in the final product; therefore, it was necessary to conduct the final bakery tests for a more accurate quality assessment.

Table 3 shows the linear correlation among the results obtained by the WGQA, farinograph, and extensigraph. In general, the linear correlation between the parameters analyzed was below 0.65 , and the highest value was obtained for RMP (WGQA) and A3 (extensigraph).

Several explanations should be considered for the linear correlation values smaller than 0.6 . As already seen, most flour samples showed medium strength characteristics; therefore, there may be large variations in parameters, such as high water holding capacity, but low resistance to extension, or vice versa, which may affect the evaluation by PCA and the linear correlation. Another factor that must be considered is that WQGA analyzes gluten after being isolated, while the other instruments analyze the flour after the addition of water and kneading, and thus the presence of other nutrients in greater amounts can affect the bonds between the flour and the water, especially in the presence of non-gluten-forming proteins, minerals, and damaged starch.

In this study, there was low correlation between the results obtained with the instruments used and those of the baking test. Lásztity (2002) found results similar to those in the present study, suggesting the need of further studies on the role of nongluten forming proteins and wheat nutrients in the baking test results.

Table 3. Linear Correlation between the farinograph, extensigraph, and WGQA parameters.

\begin{tabular}{cccccccc}
\hline Parameter $^{\mathrm{a}}$ & RMP & EXP & ENP & ABS & TD & EST \\
\hline RE1 & 0.5272 & -0.4532 & 0.1049 & 0.1365 & 0.4127 & 0.6050 \\
RE2 & 0.4518 & -0.5353 & -0.0152 & 0.0625 & 0.3313 & 0.5307 & -0.7177 \\
RE3 & 0.4884 & -0.5520 & -0.0018 & -0.0221 & 0.3197 & 0.5043 \\
RME1 & 0.5799 & -0.4686 & 0.1496 & 0.0881 & 0.428 & 0.6530 & -0.6367 \\
RME2 & 0.5397 & -0.5470 & 0.0581 & 0.0190 & 0.3328 & 0.5680 & -0.7397 \\
RME3 & 0.5667 & -0.5614 & 0.0358 & -0.0523 & 0.3593 & 0.5706 & -0.6527 \\
EXE1 & -0.0533 & 0.4331 & 0.2763 & -0.0439 & -0.0581 & -0.0960 & 0.3287 \\
EXE2 & -0.1198 & 0.5136 & 0.2516 & -0.1131 & -0.1403 & -0.2326 \\
EXE3 & -0.0087 & 0.5036 & 0.3626 & -0.0208 & -0.1107 & -0.1524 & 0.4637 \\
A1 & 0.6150 & -0.3075 & 0.2852 & 0.0929 & 0.4335 & 0.6843 & -0.6982 \\
A2 & 0.6071 & -0.3930 & 0.2001 & 0.0079 & 0.4145 & 0.6745 & -0.6940 \\
A3 & 0.6511 & -0.3995 & 0.2249 & -0.0132 & 0.3879 & 0.6341 \\
RMP & 1.0000 & -0.3342 & 0.5839 & 0.0437 & 0.1833 & -0.6625 \\
EXP & -0.3342 & 1.0000 & 0.4706 & 0.2641 & -0.0329 & -0.09702 \\
ENP & 0.5839 & 0.4706 & 1.0000 & 0.3644 & 0.0817 & -0.5079 \\
\hline
\end{tabular}

${ }^{a}$ RE1, RE2, RE3 = resistance to extension, obtained at 45, 90, and 135 minutes, respectively; RME1, RME2, RME3 = maximum resistance to extension, obtained at 45, 90 , and 135 minutes, respectively; EXE1, EXE2, EXE3 = extensibility obtained at 45, 90, and 135 minutes, respectively; Al, A2, A3 = energy obtained by the extensigraph at 45, 90, and 135 minutes, respectively; RMP, EXP and ENP = maximum resistance to extension, extensibility and energy, respectively, obtained by the WGQA; ABS, TD, EST and IT = absorption, development time, stability, and tolerance index respectively, obtained by the farinograph. 


\subsection{Baking test}

Table 4 shows the values of loaf specific volume (SV) and the baking test parameters. SV ranged from 2.78 (sample $X$ ) to $5.76 \mathrm{~cm}^{3} \mathrm{~g}^{-1}$ (samples $G$ and $o$ ). Samples 6, 8, $A, G, M, g$, and $j$ had good breadmaking performance (SV $>5.0 \mathrm{~cm}^{3} \mathrm{~g}^{-1}$ ), while samples $C, D, T, X$, and $u$ had worse $\mathrm{SV}\left(<3.6 \mathrm{~cm}^{3} \mathrm{~g}^{-1}\right)$.

According to Camargo \& Camargo (1987), in order to be considered a good quality bread, it should have a minimum score of 80 points. The authors investigated bread quality using the same parameters used in the present study but evaluated aroma and flavor, which totaled 100 points. In the present investigation, of a total of 75 points, bread samples above 60 points were considered having good quality.

As can be seen in Table 4, of the 59 samples analyzed, more than 25 had good baking quality. The final baking test showed that the flours considered strong and weak exhibited the expected results according to the rheological behavior, but the medium-strength flour exhibited variable results in the baking test, evidencing that for these flours, besides the rheological behavior, it is essential to conduct the experimental bakery test.

Figures 2 and 3 shows the PCA analysis of the baking test parameters, internal characteristics (CI), external characteristics (CE), and total score (TOT) used to evaluate the effect of the parameters obtained by farinography (Figure 2a); extensigraphy (Figure $2 \mathrm{~b}$ ), and WGQA (Figure 3).

Figure $2 \mathrm{a}$ shows that the farinograph parameters EST, TD, and ABS were important for the characteristics of the baking test. Although the vectors of the results of the farinograph and final baking test were very close the center and located between the two axes, $\mathrm{PC} 1$ showed higher contribution to the results. Figure 2a shows that samples $J, L, M, 9,3, B, 8$, $p$, and $s$ had the highest values of bread quality using the extensigraph and good performance in the baking test.

As can be seen in Figure 2b, the results of the baking test were affected by the extensigraphic parameters A3, RME3, and RE3. Samples $M, G, 8,9, J, P, S, 3$, and $B$ evidenced this fact, because they were close to the extensigraph characteristics as the bread quality characteristics, with good breadmaking performance.

In contrast, samples $E, N, Z, U, F$ and 2 were more distant from these parameters and had bad performance.

Figure 3 shows that the parameter RMP obtained by the WGQA and was close to the vector 1, combined with the results of the baking test; thus it can be considered an important parameter to predict the quality of the final product since samples $J, 3, M, B, 9,8,5, p$, and $t$ showed a greater influence on RMP and good performance in the baking test. In contrast, samples $2, F, T, U, u, N, x$, and $D$, which are located on the opposite side of the RPM vector and farther from the indicators of the baking test results, exibited poor performance.

Although the rheological instruments used in this study, including the WGQA, were able to predict the behavior of the weak and strong wheat flour in the baking test, it was not possible to predict the behavior of the medium strength flours since they resulted in products with significant variation in the (a)

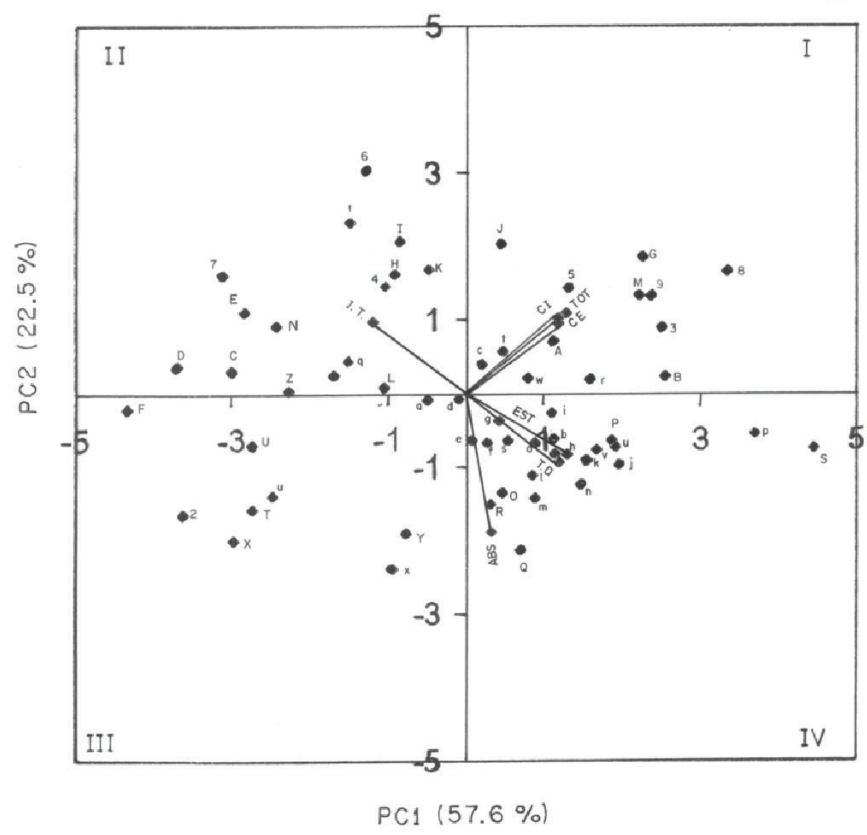

(b)

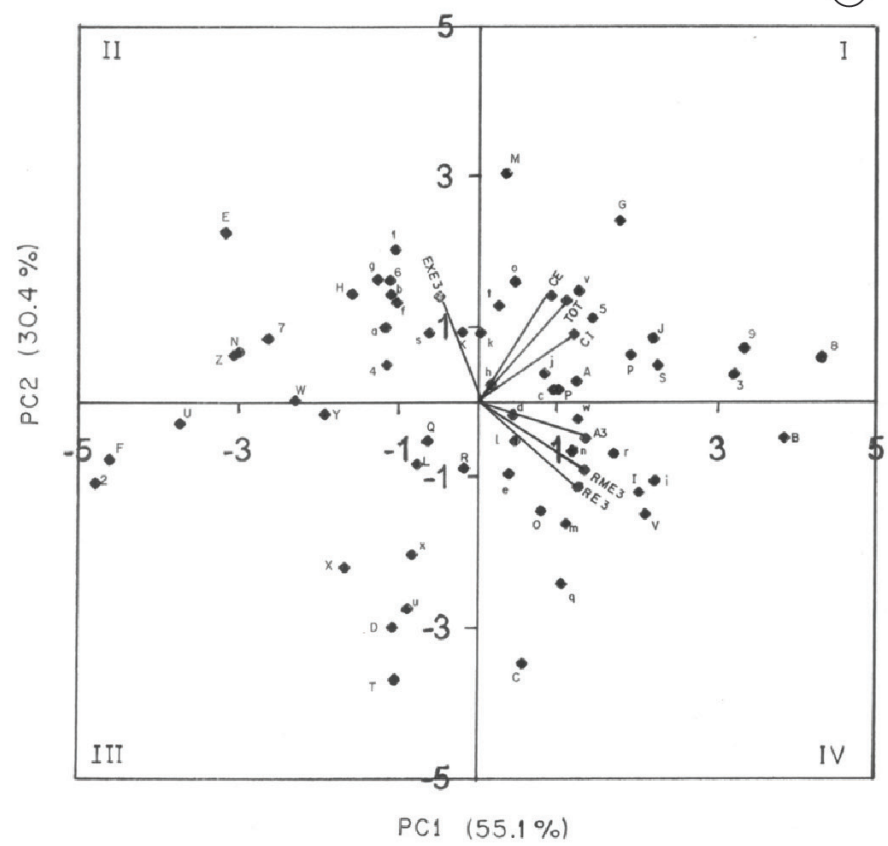

Figure 2. PCA Graph of the parameters obtained by the farinograph and baking test (a) and extensigraph and baking test (b). Where: ABS, TD, EST, and IT = absorption, development time, stability, and tolerance index respectively, obtained by the farinograph; RE3, RME3, EXE3, and A3 = resistance to extension, maximum resistance to extension, extensibility, and energy at 135 minutes, respectively, obtained by the extensigraph; $\mathrm{CE}, \mathrm{CI}$ and TOT = external characteristics, internal characteristics, and total score obtained by the baking test. 
Table 4. Loaf specific volumes $(\mathrm{SL})^{1}$; external characteristics $(\mathrm{CE})^{1}$; internal characteristics $(\mathrm{CI})^{1}$, and total score $(\mathrm{TOT})^{1}$ obtained from the baking test.

\begin{tabular}{|c|c|c|c|c|c|c|c|c|c|c|c|c|c|c|}
\hline \multirow[b]{2}{*}{ Sample } & \multicolumn{4}{|c|}{ Baking Test } & \multirow[b]{2}{*}{ Sample } & \multicolumn{4}{|c|}{ Baking Test } & \multirow[b]{2}{*}{ Sample } & \multicolumn{4}{|c|}{ Baking Test } \\
\hline & $\begin{array}{c}\mathrm{SL} \\
\left(\mathrm{cm}^{3} / \mathrm{g}\right)\end{array}$ & CE & $\mathrm{CI}$ & TOT & & $\begin{array}{c}\mathrm{SL} \\
\left(\mathrm{cm}^{3} / \mathrm{g}\right)\end{array}$ & CE & CI & TOT & & $\begin{array}{c}\mathrm{SL} \\
\left(\mathrm{cm}^{3} / \mathrm{g}\right)\end{array}$ & CE & $\mathrm{CI}$ & TOT \\
\hline 1 & 4.77 & 32.4 & 27.0 & 59.4 & $\mathrm{~L}$ & 4.28 & 29.3 & 26.5 & 55.8 & $\mathrm{f}$ & 4.63 & 32.5 & 27.5 & 60.4 \\
\hline 3 & 5.11 & 34.5 & 30.0 & 64.5 & $\mathrm{~N}$ & 4.24 & 29.1 & 26.0 & 55.1 & $\mathrm{~h}$ & 4.91 & 33.4 & 26,5 & 59,9 \\
\hline 4 & 4.68 & 32.6 & 26.5 & 59.1 & $\mathrm{O}$ & 3.70 & 30.8 & 26.0 & 55.8 & $\mathrm{i}$ & 4.73 & 33.2 & 28.0 & 61.2 \\
\hline 5 & 4.83 & 35.6 & 28.5 & 64.1 & $\mathrm{P}$ & 4.16 & 32.3 & 28.0 & 60.3 & j & 5.14 & $34 . .6$ & 27.5 & $62 . .1$ \\
\hline 7 & 3.90 & 27.5 & 26.5 & 54.0 & $\mathrm{R}$ & 4.04 & 32.0 & 25.0 & 56.0 & 1 & 4.07 & 30.6 & 27.5 & 58.1 \\
\hline 8 & 5.49 & 37.3 & 31.0 & 68.3 & S & 3.91 & 31.0 & 32.5 & 63.5 & $\mathrm{~m}$ & 4.67 & 33.0 & 26.0 & 58.0 \\
\hline 9 & 4.63 & 33.4 & 32.0 & 65.4 & $\mathrm{~T}$ & 3.10 & 24.8 & 23.0 & 47.8 & $\mathrm{n}$ & 4.85 & 34.2 & 26.0 & 60.2 \\
\hline A & 5.39 & 34.0 & 27.5 & 61.5 & $\mathrm{U}$ & 3.75 & 27.5 & 24.0 & 51.5 & o & 5.76 & 33.8 & 28.5 & 62.3 \\
\hline B & 4.68 & 34.1 & 30.0 & 64.1 & $\mathrm{~V}$ & 4.37 & 32.5 & 27.0 & 59.5 & $\mathrm{p}$ & 4.91 & 33.4 & 30.0 & 63.4 \\
\hline $\mathrm{C}$ & 3.04 & 24.1 & 26.5 & 50.6 & $\mathrm{~W}$ & 3.89 & 28.5 & 26.5 & 55.0 & $\mathrm{q}$ & 4.04 & 29.5 & 26.0 & 55.5 \\
\hline $\mathrm{H}$ & 4.74 & 32.8 & 27.0 & 59.8 & b & 4.34 & 33.0 & 26.5 & 59.5 & $\mathrm{v}$ & 4.74 & 33.3 & 29.0 & 62.3 \\
\hline I & 4.41 & 31.7 & 28.0 & 59.7 & c & 4.19 & 32.5 & 27.5 & 60.0 & $\mathrm{w}$ & 4.95 & 33.5 & 27.5 & 61.0 \\
\hline $\mathrm{J}$ & 7.87 & 34.7 & 29.5 & 64.2 & d & 4.05 & 32.3 & 27.0 & 59.3 & $\mathrm{x}$ & 3.93 & 28.1 & 24.0 & 52.1 \\
\hline $\mathrm{K}$ & 4.86 & 34.2 & 27.0 & 61.2 & e & 3.79 & 30.7 & 26.5 & 57.2 & & & & & \\
\hline $\mathrm{MP}^{2}$ & & 40.0 & 35.5 & 75.0 & & & 40.0 & 35.5 & 75.0 & & & 40.0 & 35.5 & 75.0 \\
\hline
\end{tabular}

${ }^{1}$ Mean of two replicates. ${ }^{2} \mathrm{MP}=$ maximum score.

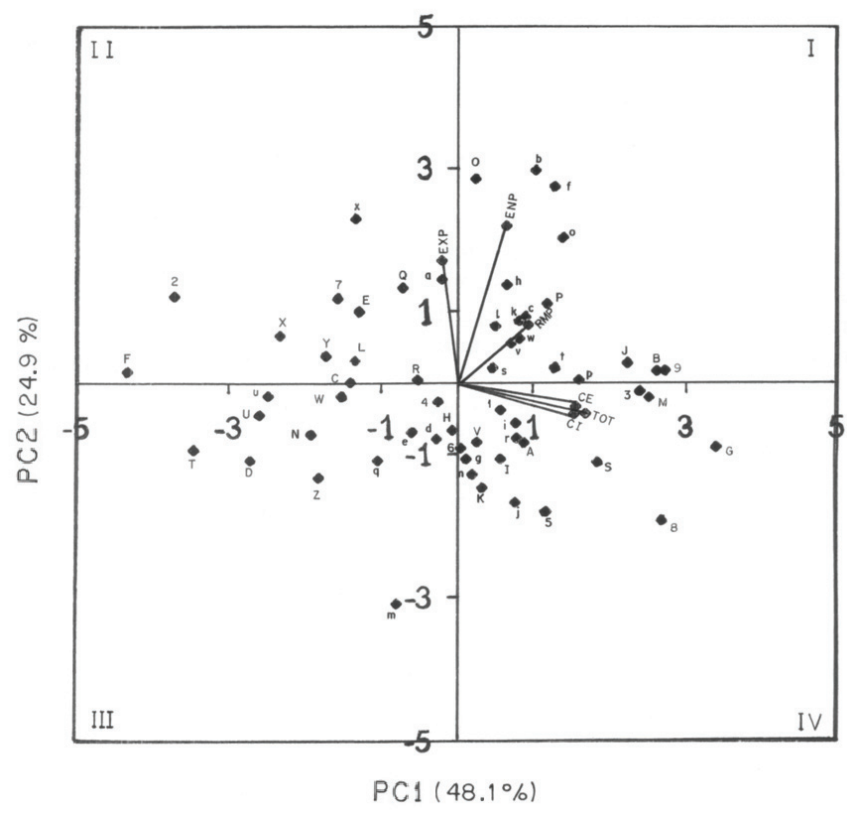

Figure 3. PCA graph of the parameters obtained by the WGQA and baking test. RMP, EXP and ENP = maximum resistance to extension, extensibility, and energy, respectively, obtained by the WGQA; CE, CI and TOT $=$ external characteristics, internal characteristics, and total score, obtained by the baking test.

final quality. WGQA was capable of identifying the samples with good and bad performance for baking; thus they are more advantageous than the farinograph and extensigraph due to the use of wet gluten from the gluten test, in addition to the small amounts of sample and very fast analysis time, which differentiates it from other instruments.

\section{Conclusion}

The WGQA apparatus described in this study proved useful to evaluate the physical properties of wheat gluten. The maximum resistance to extension (RMP) obtained by the WGQA was more effective in predicting the good performance of the wheat flours in the baking test. The results obtained by the WGQA were the same as those determined by the other rheological instruments during the assesment of the effect of the rheological properties of wheat flour by the baking test. All instruments analyzed were effective in anticipating the results of strong or weak strength flours, but they they were not as effective in anticipating the results of medium strength flour in the baking test. The great advantage of WQGA is the use of wet gluten from the gluten test, thus requiring less amount of sample and enabling very fast analysis time, which differentiates it from the other instruments.

\section{Acknowledgments}

We do hereby thank the Foundation for Support of Research of the State of São Paulo (FAPESP) for supporting this research.

\section{References}

American Association for Clinical Chemistry - AACC. (1995). Approved Methods. St. Paul: AACC.

Associação Brasileira da Indústria do Trigo - Abitrigo. (2014). Retrieved from http://www.abitrigo.com.br/. 
Baker, J. C., Parker, H. K., \& Mize, M. D. (1942). The action of an oxidizing agent in bread dough made from patent flours. Cereal Chemistry, 19, 334-46.

Baker, J. C., Parker, H. K., \& Mize, M. D. (1943). Measurement and significance of gluten quality. Cereal Chemistry, 20, 506-16.

Bloksma, A. H. (1990). Rheology of the breadmaking process. Cereal Foods World, 35, 228-236.

Camargo, C. R. O., \& Camargo, C. E. O. (1987). Trigo: avaliação tecnológica de novas linhagens. Bragantia, 46(2), 169-181. http:// dx.doi.org/10.1590/S0006-87051987000200002

Chang, Y. K. (1994). Wheat gluten quality analyser. BR Patent No. I40 1844-8.

Chang Y. K., \& Ferrari, M. C. (2000). A new apparatus for the evaluation of rheological properties of wheat gluten. Acta Alimentaria, 29(2), 169-80. http://dx.doi.org/10.1556/AAlim.29.2000.2.7

Costa, M. G., Souza, E. L., Stamford, T. L. M., \& Andrade, S. A. C. (2008). Qualidade tecnológica de grãos e farinhas de trigo nacionais e importados. Food Science and Technology, 28(1), 220-225.

Dendy, D. A. V., \& Dobraszczyk, B. J. (2001). Cereals and Cereal Products: Technology and Chemistry (Food Products Series, Vol. 4). Ed. Springer.

Dobraszczyk, B. J., Campbell, G. M., \& Gan, Z. (2001). Bread: a unique food. In B. J. Dobraszczyk \& D. A. V. Dendy (Eds.), Cereals \& Cereal Products: Chemistry and Technology (pp. 182-232). Maryland: Aspen Publishers.

El-Dash, A. A. (1978). Analysis and development of a new system for testing the technological quality of flours. UNICAMP.

Food and Agriculture Organization of the United Nations - FAO. (2013). FAOStat. Retrieved from http://faostat.fao.org/site/339/ default.aspx.

Fufa, H., Baenziger, P. S., Beecher, B. S., Dweikat, I., Graybosch, R. A., \& Eskridge, K. M. (2005). Comparison of phenotypic and molecular marker-based classifications of hard red winter wheat cultivars. Euphytica, 145(2), 133-146. http://dx.doi.org/10.1007/ s10681-005-0626-3

Hlynkla, K., \& Anderson, J. A. (1946). A machine for measuring the extensibility and resistente to extension of gluten. Cereal Chemistry, $23,115-34$.
James, T. R., \& Huber, L. X. (1927). A study of the physical properties of washed gluten. Cereal Chemistry, 4, 449-60.

Kress, C. B. (1924). Gluten quality. Cereal Chemistry, 1, 247-50.

Lásztity, R. (2002). Prediction of wheat quality - success and doubts. Periodica Polytechnica Ser. Chem. Eng, 46(1-2), 39-49.

Módenes, A. N., Silva, A. M., \& Trigueros, D. E. G. (2009). Avaliação das propriedades reológicas do trigo armazenado. Food Science and Technology, 29(3), 508-512. http://dx.doi.org/10.1590/S010120612009000300008

Mohs, K., Schimidt, E. A., \& Frank, H. V. (1939). Die Bestimmung der Kleberdehnberkeit mittels des Glutographen. $Z$ ges Getreide Muhlenw, 26, 23-30.

Oliver, J. R., \& Allen, H. M. (1992). The prediction of bread baking performance using the farinograph and extensograph. Journal of Cereal Science, 15(1), 79-89. http://dx.doi.org/10.1016/S07335210(09)80058-1

Pomeranz, Y. (1988). Wheat chemistry and technology (3rd ed.). St. Paul: AACC.

Pratt, D. B. (1971). Criteria of flour quality. In Y. Pomeranz (Ed.). Wheat: Chemistry and Technology (pp. 201-226). St. Paul: AACC.

Schiller, G. W. (1984). Bakery four specifications. Cereal Foods World, 29, 647-51.

Schmidt, D. A. M., Carvalho, F. I. F., Oliveira, A. C., Silva, J. A. G., Bertan, I., Valério, I. P., Hartwig, I., Silveira, G., \& Gutkoski, L. C. (2009). Variabilidade genética em trigos brasileiros a partir de caracteres componentes da qualidade industrial e produção de grãos. Bragantia, 68(1), 43-52. http://dx.doi.org/10.1590/S000687052009000100006

Sietz, W., \& Dorfner, H. H. (1987). Gluten quality testing - a new method. Getreide Mehl und Brot, 41, 16-9.

Statistical Analisys System Institute - SAS. (1990). SAS/STAT user's guide: version 6. SAS Inst.

Udy, D. C. (1953). Effect of bisulfite and thioglycolic acid on the viscosity of wheat gluten dispersions. Cereal Chemistry, 30, 288-301.

Williams, P., El-Harmamein, F. J., Nakkaoul, H., \& Rihawi, S. (1988). Crop quality evaluation methods and guideline (2nd ed.). Aleppo: ICARDA. 